\title{
Users' Perspective of Extensible Business Reporting Language (XBRL) in India
}

\author{
S. Raghavendra Raju* and B. Mahadevappa**
}

\begin{abstract}
There has been a paradigm shift in financial reporting after the introduction of Extensible Business Reporting Language (XBRL). XBRL is a language for electronic communication of business and financial data. The Ministry of Corporate Affairs of Government of India has mandated e-filing of annual reports for certain class of companies in XBRL format from April 1, 2011. Now, more than 1 lakh companies are filing their financial statements through XBRL. The purpose of this paper is to know the users' awareness about XBRL. The sample for the study includes 76 users. Research instrument was constructed to collect the primary data from the respondents. Hypothesis was tested to know the difference in the users' perspective about XBRL. The results of the study were presented in five qualitative characteristics: understandability, reliability, relevance, comparability, and timeliness. The results of the paper indicate that there is more understandability, reliability, and relevance of financial statements among the users along with easier comparison of XBRL reports across companies.
\end{abstract}

Keywords: XBRL; Taxonomy; Instance document; Qualitative characteristics.

\subsection{Introduction}

With the increase in the frauds and scams in the last two decades, there have been doubts in the minds of the stakeholders about the functioning of various organisations. Transparency and integrity was very much required, and there was a need for better technology based reporting. In response to this need, XBRL was developed as the solution. Extensible Business Reporting Language (XBRL) is the electronic communication of business reporting. XBRL is an open and free standard which means no license fees have to be paid by the user.

*Research Scholar, University of Mysore. (email: raganna20@gmail.com)

**Professor, DOS in Commerce, University of Mysore.

(email: bmahadevappa@gmail.com) 
XBRL is based on XML, which is a set of rules for encoding documents. It has been compared to introduction of bar coding and to the introduction of ISBN number for books. An Extensible language means one that is designed to easily allow the addition of new features at a later date. XBRL is not about sharing more information but about improving the information is shared. It is the fundamental transformation in which business information is exchanged.

XBRL was conceived in 1998 by a CPA named Charles Hoffman based on Extensible Markup language (XML). Hoffman (1998) defines XBRL as follows: "XBRL is an open standard which supports information modelling and the expression of the semantic meaning commonly required in business reporting”. XBRL International (2009) defines XBRL as "A language for the electronic communication of business and financial data which is revolutionizing business reporting around the world". It provides major benefits in the preparation, analysis and communication of business information. It offers cost savings, greater efficiency and improved accuracy and reliability to all those involved in supplying or using financial data.

XBRL works with two documents: Taxonomy and Instance Document. Taxonomy is the science of classification; it is the electronic dictionary of the reporting concepts. It is created according to the accounting rules and regulations of a country and so it is country-specific. Instance documents are those that are immediately processable by another XBRL enabled application. The data in the instance document is only numbers, texts and brackets and thus it is not normally viewed by a person in its raw form. A style sheet application is needed to convert the XBRL data in an instance document and then into a traditional looking financial statement.

\subsection{Working of XBRL}

The source document is the annual report of the company that is to be converted to XBRL. In general, it means a catalogue or set of rules for classification. In XBRL, it means electronic dictionary of the reporting concepts containing computer readable definitions of business reporting. The process of mapping the financial data to unique element is called tagging.

XBRL will be a big change from the current reporting practices where the exchange of information is done via non-interchangeable forms like PDF, spreadsheets or HTML. $\mathrm{XBRL}$ is expected to have widespread effects on financial reporting and beneficiaries are not limited to only accountants but are said to include also company management, creditors, analysts and regulators. 
The key benefits to users who spend long hours analysing company's financial statements is that XBRL solutions reduce costs, increase productivity, improve data quality, and extend the inter-operability of the data. XBRL India is the Indian Jurisdiction of XBRL International. Its main objective is to promote and encourage the adoption of XBRL in India as the standard for electronic business reporting. From April 1, 2011, the Ministry of Corporate Affairs has mandated e-filing of annual reports for certain specified class of companies in XBRL format. Around 50,000 companies file XBRL financial statements every year. The following are the companies which need to file in XBRL format:

a) Companies listed in India and their Indian subsidiaries;

b) Companies having a paid up capital of ₹ 5 crore and above; and

c) Companies having a turnover of ₹ 100 crore and above.

Apart from MCA, Securities and Exchange Board of India (SEBI), Bombay Stock Exchange and Reserve Bank of India are also involved in effective implementation of XBRL. SEBI had implemented super-D project based on XBRL platform. BSE has mandated mandatory filing of corporate governance report and shareholding pattern in XBRL mode. RBI has its own online financial reporting system in XBRL mode.

\subsection{Need for the Study}

A lot has been talked about the accounting aspects of business but there has been less stress on the reporting aspects of the business the world over. With different reporting formats for each country, a common language of reporting for the business to interact was required, and XBRL provided a solution for the same. XBRL was mandated in India from 2011 for a certain class of companies. So a study was needed in order to know the users' perceptive of XBRL. Users for this study consist of researchers, practicing Company Secretaries and practicing Chartered Accountants. Since 2011, there have been tremendous changes in the financial reporting so it was important to know about the understandability, reliability, relevance, comparability and timeliness of financial reporting. Further, we attempt to find whether there was a reduction in processing errors after XBRL was mandated.

\subsection{Review of Literature}

Vasal and Srivastava (2002) highlight how XBRL can be useful for India. The primary objective of the study was to investigate some of the major issues in delivery of 
business information through the Web using the 'digital' language of business called the Extensible Business Reporting Language (XBRL). The findings of the study indicate that as a technology, XBRL is attempting to provide a digital language (digital) to the (electronic) accounting statements. XBRL shall enable financial reports to converse across all software and technologies. The research opportunities are many; firstly, since a large number of countries have some uniqueness associated with their respective GAAP, there are ample opportunities available for academic and the professional accountants to devise XBRL taxonomies appropriate to their accounting set-up. These taxonomies could be devised for commercial and industrial enterprises, not-for-profit organizations, mutual funds and various other major and unique business groups. Secondly, the information displayed through the notes to accounts and, management discussion and analysis sections of the annual reports lastly coding of accounting data in XBRL shall facilitate effective institutionalisation of the processes of continuous monitoring and continuous reporting in the business organisations.

Kashyap and Garg (2013) examine various errors in MCA XBRL filings. MCA had examined various errors in the first year of XBRL implementation and found several errors in XBRL filings by companies. This was brought out in a circular titled "quality of XBRL filing certified by Professional members". However, in second year it had brought major changes. To gain a better insight, the authors examine the XBRL financial statements of a few listed companies for the financial year 2011-12 on a test check basis. They find errors namely completeness errors, mapping errors, consistency errors and structural errors. The authors conclude that the reliability of XBRL tagged data is compromised by errors in XBRL filings and can adversely affect the investors' perception about XBRL financial statements filed at MCA. It is only when the quality of XBRL tagged data is high, the end users of financial statements will start using this data and the real benefits of XBRL in more quick and efficient analysis will be realised.

Farewell et al (2013) describe the MCA e-governance initiative and XBRL implementation. As much academic XBRL research was focussed on US market, there was a need to see how non-US countries have implemented XBRL. So this study concentrates on XBRL implementation in India. Indian implementation was unique because it is first known requiring auditor certification on XBRL filings. So the study has implications for auditors in global networks as well as for firms who operate in India and in countries where the regulator is considering a similar XBRL implementation plan. The MCA identified several benefits like cost savings, accuracy of data, ease of access to data. However, MCA implementation process had many problems. Firstly, taxonomy contained architectural deficiencies. The Indian taxonomy is a closed taxonomy (i.e., no extensions allowed- all tags must be part of the prescribed taxonomy). So it has been 
difficult for non-Indian subsidiaries who used unique general ledger accounts to convert their financial statements consistent with the taxonomy. Secondly, the credibility of the independent XBRL certification process can be questioned. Thirdly, XBRL filings in general have contained various errors or discrepancies; an examination of a sample of 15 listed companies and the comparison with their audited financial statements in traditional format indicated significant errors in XBRL documents which could adversely affect the automated analysis of various companies' data.

\subsection{Objectives and Hypotheses}

The main objective of the study is to understand the users' perspective on availability, utility, requirements and qualitative characteristics of XBRL reporting in India

\section{Hypotheses}

Ho: There is no significant difference in the users' perspective on qualitative characteristics of XBRL reporting.

H1: There is a significant difference in the users' perspective on qualitative characteristics of XBRL reporting.

\subsection{Methodology}

The study was conducted to know the users perception of XBRL. For this, questionnaire instrument was constructed consisting of 26 variables divided into 5 qualitative characteristics of financial reporting factors namely understandability, reliability, relevance, comparability and timeliness. Apart from this availability, and usefulness of XBRL was also considered.

\subsection{Sample}

Data were collected from 76 users out of 300 email invitees which constituted 25.33\% of the invitees. Users include researchers, practicing Chartered Accountants and practicing Company Secretaries spread all over India.

\subsection{Research instrument}

Research Instrument was constructed consisting of 26 variables classified into qualitative characteristics of Financial reporting which is shown in Table 1. 
34 | MUDRA: Journal of Finance and Accounting, Volume 3, Issue 2

Table 1: Qualitative Characteristics of XBRL reporting

\begin{tabular}{|l|l|l|}
\hline $\begin{array}{l}\text { S. } \\
\text { No }\end{array}$ & Scale & Items \\
\hline 1 & $\begin{array}{l}\text { Understandability } \\
\text { It is the information to be presented in a } \\
\text { way that is readily understandable by } \\
\text { users. }\end{array}$ & $\begin{array}{l}\text { This factor contains information whether } \\
\text { users of financial information understands } \\
\text { XBRL Taxonomy, whether it is easy or } \\
\text { difficult, whether more time and effort is } \\
\text { needed to understand it; and if frequent } \\
\text { changes in taxonomy is a bottleneck in } \\
\text { understanding financial reports. }\end{array}$ \\
\hline 2 & $\begin{array}{l}\text { Reliability } \\
\text { Information has the quality of reliability } \\
\text { when it is free from material error and } \\
\text { bias and can be depended upon by users } \\
\text { to represent faithfully which it either } \\
\text { purports to represent or could reasonably } \\
\text { be expected to represent. }\end{array}$ & $\begin{array}{l}\text { This factor contains information whether } \\
\text { XBRL filings are accurate, XBRL } \\
\text { financial reports are reliable source for } \\
\text { financial decision making and the same } \\
\text { financial reports can be re-used with no } \\
\text { loss of data integrity. }\end{array}$ \\
\hline 4 & $\begin{array}{l}\text { Relevance } \\
\text { decrmation is relevant if it influences the } \\
\text { assisting them in evaluating past, present } \\
\text { and future events. }\end{array}$ & $\begin{array}{l}\text { This factor contains information whether } \\
\text { XBRL financial reports are done as per } \\
\text { the provisions of the Companies Act and } \\
\text { Accounting standards. }\end{array}$ \\
\hline 5 & $\begin{array}{l}\text { Comparability } \\
\text { It is the quality of information that } \\
\text { enables users to identify similarities in } \\
\text { and differences between two sets of } \\
\text { economic phenomena. }\end{array}$ & $\begin{array}{l}\text { This factor contains information whereby } \\
\text { XBRL Financial reports are very useful } \\
\text { for intra-firm and inter-firm comparison } \\
\text { and also it can be easily shared across } \\
\text { companies and stakeholders. }\end{array}$ \\
\hline 6 & $\begin{array}{l}\text { Timeliness } \\
\text { if there is undue delay in the reporting of }\end{array}$ & $\begin{array}{l}\text { This factor contains information about the } \\
\text { time taken in generating reports; whether } \\
\text { it is much faster in XBRL and time lag in } \\
\text { XBRL is much less compared to manual } \\
\text { reports previously filed. }\end{array}$ \\
\hline
\end{tabular}

\subsection{Item to scale correlation}

Item to scale correlation was performed on the qualitative characteristics of XBRL reporting (Table 2). This is necessary in order to know whether particular variable will fit into particular characteristic. Item having high correlation with others will fit into that particular characteristic or the factor. 
Table 2: Results of Item to Scale Correlation of users

\begin{tabular}{|l|l|l|l|l|l|}
\hline \multicolumn{4}{|l|}{ Scale } \\
\hline & $\mathbf{1}$ & $\mathbf{2}$ & $\mathbf{3}$ & $\mathbf{4}$ & $\mathbf{5}$ \\
\hline 1.Understandability & & & & & \\
1.1-Understand XBRL taxonomy & $\mathbf{0 . 4 7 2}$ & 0.305 & 0.115 & 0.282 & 0.212 \\
1.2-Taxonomy is difficult to understand & $\mathbf{0 . 7 4 5}$ & -0.128 & -0.146 & -0.191 & -0.102 \\
1.3-More time and effort is needed & $\mathbf{0 . 6 8 7}$ & -0.126 & 0.063 & -0.059 & -0.209 \\
1.4-Bottleneck in understanding reports & $\mathbf{0 . 6 7 9}$ & 0.009 & -0.016 & -0.089 & 0.209 \\
2.Realiability & & & & & \\
2.1-XBRL filings are accurate & 0.075 & $\mathbf{0 . 7 1 1}$ & 0.317 & 0.448 & 0.502 \\
2.2-XBRL reports are understandable & -0.045 & $\mathbf{0 . 8 4 9}$ & 0.385 & 0.656 & 0.528 \\
2.3-XBRL reports are reliable in decision & -0.095 & $\mathbf{0 . 7 7 1}$ & 0.586 & 0.681 & 0.434 \\
2.4-XBRL reports can be re-used & 0.179 & $\mathbf{0 . 6 4 9}$ & 0.460 & 0.541 & 0.267 \\
3.Relevance & & & & & \\
3.1-Based on the prov of companies act & 0.026 & 0.616 & $\mathbf{0 . 9 1 4}$ & 0.632 & 0.307 \\
3.2-Based on the Indian accounting stds & $-0-019$ & 0.439 & $\mathbf{0 . 9 1 7}$ & 0.437 & 0.102 \\
4..Comparability & & & & & \\
4.1-Analyze/interpret XBRL reports & 0.189 & 0.458 & 0.216 & $\mathbf{0 . 6 0 2}$ & 0.372 \\
4.2-Useful for intra-firm comparison & -0.070 & 0.664 & 0.634 & $\mathbf{0 . 8 8 3}$ & 0.456 \\
4.3-Useful for inter-firm comparison & -0.030 & 0.647 & 0.599 & $\mathbf{0 . 8 8 4}$ & 0.447 \\
4.4-Shared across companies & -0.139 & 0.707 & 0.416 & $\mathbf{0 . 8 2 9}$ & 0.589 \\
5.Timeliness & & & & & \\
5.1-Easily understand than manual reports & -0.115 & 0.467 & 0.211 & 0.536 & $\mathbf{0 . 7 9 5}$ \\
5.2-Generating reports is much faster & 0.064 & 0.444 & 0.153 & 0.457 & $\mathbf{0 . 8 3 5}$ \\
5.3-Time lag is less compared to maual & -0.047 & 0.551 & 0.187 & 0.459 & $\mathbf{0 . 8 4 6}$ \\
reports & & & & & \\
\hline
\end{tabular}

\subsection{Reliability analysis}

Reliability of a measure is established by testing for both consistency and stability. Consistency indicates how well the items measuring a concept hang together as a set. Cronbach's alpha is a reliability coefficient that indicates how well the items in a set are positively correlated to one another. Reliability of a measure indicates the extent to which it is without bias and hence ensures consistent measurement across various items in the instrument. Higher values of alpha indicate higher reliability. Reliability analysis was done on the research instrument and the result of which is shown in Table 3. Reliability values for all the scale are greater than 0.70 except for understandability 
which indicates there is high internal consistency among the factors other than understandability.

Table 3: Results of Reliability Analysis

\begin{tabular}{|l|l|l|l|l|}
\hline Scale & N & Mean & SD & Cronbach Alpha \\
\hline Understandability & 4 & 3.34 & 0.94 & 0.532 \\
\hline Reliability & 4 & 3.13 & 1.09 & 0.737 \\
\hline Relevance & 2 & 3.63 & 0.89 & 0.807 \\
\hline Comparability & 4 & 2.74 & 1.05 & 0.814 \\
\hline Timeliness & 3 & 2.86 & 1.13 & 0.766 \\
\hline
\end{tabular}

\subsection{Results}

(i) Availability: It means whether financial statements are available at proper time to the users (Table 4). From Table 4, we can interpret that there is an equal proportion that for understanding XBRL related financial statements, taxonomy concepts are readily available and more than $68.4 \%$ of the users agree that XBRL related software are available. There are many service providers who are providing XBRL.

\section{Table 4: Mean Scores and Standard Deviation of Availability}

\begin{tabular}{|l|l|l|l|}
\hline & SA/A & Mean & SD \\
\hline $\begin{array}{l}\text { 1.Availability } \\
\begin{array}{l}\text { 1.1-For Understanding xbrl related financial statements taxonomy } \\
\text { concepts are readily available }\end{array}\end{array}$ & $\mathbf{5 3 . 9 5}$ & $\mathbf{3 . 2 7}$ & $\mathbf{0 . 9 5}$ \\
$\begin{array}{l}\text { 1.2-XBRL related software's are readily available } \\
\text { (n) }\end{array}$ & 68.4 & 3.62 & 0.87 \\
\hline
\end{tabular}

(ii) Usefulness of XBRL: With the use of XBRL, there will be transparency in the functioning of the organisation, reduction in reporting time, reduction in errors and also it will facilitate paperless financial reporting. Better analysis and comparison is possible because XBRL taxonomy is based on provisions of Companies Act and accounting standards. From Table 5, we can understand that nearly 53\% of the users agreed that XBRL is very useful. Over $60 \%$ of the respondents agreed that XBRL facilitates paperless reporting, reduce processing errors and XBRL generated reports will meet the requirements of regulators, lenders and other users of financial information. $47 \%$ of the users disagreed about usefulness of XBRL reporting. Many of the users are not aware 
about XBRL as a reporting tool. The reason may be lack of awareness of the technology. Nearly $58 \%$ of the users disagreed that XBRL reduces reporting time. This indeed is a serious issue as any new technology for that matter must reduce the time. However, the users disagreed on that, which may be due to inadequate training, inexperienced staff handling XBRL.

Table 5: Mean Scores and Standard Deviation of Usefulness of XBRL

\begin{tabular}{|c|c|c|c|}
\hline & $\begin{array}{l}\text { Strongly Agree/ } \\
\text { Agree }\end{array}$ & Mean & SD \\
\hline 1.Usefulness of XBRL & 52.98 & 3.22 & 1.10 \\
\hline 1.1-Users of financial information are aware of XBRL for & 39.4 & 2.91 & 1.11 \\
\hline financial reporting & 60.5 & 3.18 & 1.14 \\
\hline $\begin{array}{l}\text { 1.2-Use of XBRL will facilitate paperless financial } \\
\text { reporting }\end{array}$ & 57.9 & 3.38 & 1.21 \\
\hline 1.3-With XBRL filings there is much more transparency & 27.6 & 2.57 & 1.14 \\
\hline $\begin{array}{l}\text { in the functioning of the organization } \\
\text { 1.4-XBRL reduces reporting time }\end{array}$ & 64.5 & 3.51 & 1.11 \\
\hline 1.5-XBRL can help to reduce processing error & 63.2 & 3.55 & 1.05 \\
\hline $\begin{array}{l}\text { 1.6-XBRL generated reports will meet the requirements of } \\
\text { regulators, lenders and other users of financial } \\
\text { information } \\
1.7 \text {-XBRL generated reports will meet the requirements of } \\
\text { regulators }\end{array}$ & 57.9 & 3.49 & 0.95 \\
\hline
\end{tabular}

(iii) Qualitative characteristics of XBRL reporting: The qualitative characteristics of XBRL reporting are classified into understandability, reliability, relevance, comparability and timeliness which have been summarised in Table 6. From Table 6, we can understand the following about various aspects of XBRL reporting.

From Table 6 we can analyse that

Understandability: Nearly 58\% of the users agreed that understanding of XBRL related concepts is difficult. $63.2 \%$ of the users disagreed that users of financial information understands XBRL taxonomy. This may be due to the frequent changes in the taxonomy and also it contains exhaustive list of items. $57 \%$ of the users agreed that understanding of XBRL taxonomy is very difficult. It contains more relationships and taxonomy differs from one company to other. $83 \%$ of the users agreed that more time and effort is needed. $74 \%$ of the users felt that frequent changes in taxonomy is a bottleneck in 
understanding financial reports. This is because with the frequent changes in the taxonomy it is very difficult for the users to interpret the financial statements.

Table 6: Mean scores and SD of Qualitative Characteristics of XBRL Reporting

\begin{tabular}{|c|c|c|c|}
\hline & $\begin{array}{l}\text { Strongly } \\
\text { agree/ Agree }\end{array}$ & Mean & SD \\
\hline $\begin{array}{l}\text { 1.Understandability } \\
\text { 1.1-Users of financial information understands XBRL } \\
\text { taxonomy. } \\
\text { 1.2-The understanding of XBRL taxonomy is very difficult. } \\
\text { 1.3-To understand XBRL more time and effort is needed. } \\
\text { 1.4-Frequent changes in taxonomy is a bottle neck in } \\
\text { understanding reports. }\end{array}$ & $\begin{array}{l}\mathbf{5 7 . 9} \\
18.4 \\
56.6 \\
82.9 \\
73.7\end{array}$ & $\begin{array}{l}\mathbf{3 . 3 4} \\
2.41 \\
3.39 \\
3.87 \\
3.71\end{array}$ & $\begin{array}{l}\mathbf{0 . 9 4} \\
0.95 \\
0.96 \\
0.88 \\
0.96\end{array}$ \\
\hline $\begin{array}{l}\text { 2.Reliability } \\
\text { 2.1-XBRL filings are accurate. } \\
\text { 2.2-The information presented in XBRL reports are easily } \\
\text { understandable. } \\
\text { 2.3-XBRL generated reports are reliable sources in financial } \\
\text { decision making. } \\
\text { 2.4-XBRL based reports can be re-used with no loss in data } \\
\text { integrity. }\end{array}$ & $\begin{array}{l}47.0 \\
34.2 \\
43.5 \\
50.0 \\
60.5\end{array}$ & $\begin{array}{l}\mathbf{3 . 1 3} \\
2.84 \\
2.87 \\
3.30 \\
3.54\end{array}$ & $\begin{array}{l}\mathbf{1 . 0 9} \\
1.14 \\
1.24 \\
1.08 \\
0.90\end{array}$ \\
\hline $\begin{array}{l}\text { 3.Relevance } \\
\text { 3.1-XBRL is based on the provisions of Companies Act. } \\
\text { 3.2-XBRL is based on the Indian Accounting Standards. }\end{array}$ & $\begin{array}{l}\mathbf{6 9 . 0 5} \\
72.3 \\
65.8\end{array}$ & $\begin{array}{l}\mathbf{3 . 6 3} \\
3.68 \\
3.59\end{array}$ & $\begin{array}{l}\mathbf{0 . 8 9} \\
0.88 \\
0.89\end{array}$ \\
\hline $\begin{array}{l}\text { 4.Comparability } \\
\text { 4.1-Users of financial information are able to } \\
\text { analyze/interpret the XBRL generated reports. } \\
\text { 4.2-XBRL generated financial statements are very useful for } \\
\text { intra-firm comparison. } \\
\text { 4.3-XBRL generated financial statements are very useful } \\
\text { for inter-firm comparison. } \\
\text { 4.4-XBRL reports can be easily shared across companies } \\
\text { and stakeholders. }\end{array}$ & $\begin{array}{l}\mathbf{5 3 . 6 2} \\
31.6 \\
63.2 \\
61.8 \\
57.9\end{array}$ & $\begin{array}{r}2.74 \\
2.75 \\
3.62 \\
\\
3.58 \\
1.04\end{array}$ & $\begin{array}{l}1.01 \\
1.04 \\
1.13\end{array}$ \\
\hline $\begin{array}{l}\text { 5. Timeliness } \\
\text { 5.1-XBRL reports are easily understandable compared to } \\
\text { manual reports. } \\
\text { 5.2-In XBRL the time taken in generating XBRL reports is } \\
\text { much faster. } \\
5.3 \text {-The time lag is much less compared to manual reports. }\end{array}$ & $\begin{array}{l}\mathbf{3 6 . 8 3} \\
31.6 \\
40.8 \\
38.1\end{array}$ & $\begin{array}{l}\mathbf{2 . 8 6} \\
2.75 \\
2.99 \\
2.86\end{array}$ & $\begin{array}{l}\mathbf{1 . 1 3} \\
1.13 \\
1.13 \\
1.14\end{array}$ \\
\hline
\end{tabular}


Reliability: $47 \%$ of the users agreed that XBRL filings of reports are reliable. It is the quality of information that assures decision makers that the information represented in the financial records captures the actual conditions and events of the reporting entity. $46 \%$ of the users felt that XBRL filings are not accurate and not easily understandable. This may be due to changes in the taxonomy and that XBRL is not free from material errors. $50 \%$ of the users agreed that XBRL generated reports are reliable sources in decision making. Over $60 \%$ of the users agreed that XBRL reports can be reused and filed to different regulators. With this re-usablility of the same XBRL financial reports is possible.

Relevance: MCA XBRL is based on the provisions of the Companies Act and Indian Accounting Standards. Nearly $70 \%$ of the users agreed to this factor. In any country for that matter XBRL is based on the regulations and provisions of that country. Taxonomy will be developed as per the provisions of the Companies Act, it will be changing as and when there is change in law and regulations. More than $65 \%$ of the users agreed that XBRL is based on the provisions of the Companies Act and Indian Accounting Standards.

Comparability: $49 \%$ of the users felt that it is difficult to analyse and interpret the XBRL generated reports. This might be due to lack of understanding of business concepts and taxonomy. Over $60 \%$ of the users agreed that XBRL reports are very useful for interfirm and intra-firm comparison. 58\% of the users agreed that XBRL reports can be easily shared across companies and stakeholders. It fulfills the inter-operability of financial statements.

Timeliness: Only $37 \%$ of the users agreed on the timeliness characteristic. $32 \%$ agreed that XBRL generated reports are easily understandable than manual reports previously filed. Not many people agreed to the fact that time taken for generating reports is much faster. This may be due to technology issues, proper mapping of the financial statements. What manual filings used to do in days XBRL will do in minutes. However, this needs to be rechecked with more data and filings in place. There is a not much difference also for the time lag for filing XBRL reports.

The results of the ANOVA given in Table 7 rejects the null hypothesis and accept the research hypothesis as the $\mathrm{F}$ Value is 9.375 at $1 \%$ significant level which indicates that there is significant difference in the users' perspective on the qualitative characteristics of XBRL reporting. Base on users' perspective, the study found that improvements in qualitative characteristics of XBRL reporting will enhance the quality of reporting. 
Table 7: Result of ANOVA

\begin{tabular}{|l|l|l|l|l|l|}
\hline Users perspective & Sum of Squares & Df & Mean square & F & Sig \\
\hline Between Groups & 24.761 & 4 & 6.190 & 9.375 & 0.0001 \\
Within groups & 247.611 & 375 & 0.660 & & \\
Total & 272.372 & 379 & & & \\
\hline
\end{tabular}

$p$-value is significant at $<0.05$ level

\subsection{Conclusion}

From the study we can conclude that regarding availability, there are XBRL softwares readily available to suit the users. Regarding qualitative characteristics, such as 'understandability', it has been observed that XBRL taxonomy is difficult to understand and it must be made more user-friendly. Many respondents felt that regular change of taxonomy is a bottleneck and proper training must be given to understand it. Secondly, regarding 'reliability' many respondents disagreed that XBRL filings are accurate which is a major concern; however, this may be improved when more number of samples are taken. Thirdly, regarding 'relevance', the XBRL taxonomy are prepared according to the provisions of the Companies Act and Indian Accounting Standards many respondents agreed to it. Fourthly, users are not in a position to interpret the XBRL generated reports this may be improved by proper training. Lastly regarding timeliness there is not much significant difference. However many users felt that XBRL will help in reducing processing errors and bring transparency in the functioning of organisation. Further studies should focus on taking more number of samples and also on other qualitative characteristics like faithful representation, verifiability and materiality.

\section{References}

Farewell, S., Hao, L., Kashyap, V. \& Pinkser, R. (2013). A Case Study examining the Indian Ministry of Corporate Affairs XBRL Implementation.

Retrievedfrom http://eycarat.faculty.ku.edu/myssi/XBRL2013/2.Farewell,\%20Hao,\%20 Kashyap\%20\&\%20Pinsker.pdf

Hoffman, Charles. \& Watson, Apneseth Liv. (2010). XBRL for Dummies. New Jersey: Wiley Publishing Inc. 
Kashyap, V., \& Garg , N.(2013). Ah., Again there is an error in XBRL. The Chartered Accountant, 444-448.

Vasal,V.K., \& Srivastava,R.P.(2002). Extensible Business Reporting Language (XBRL) -The digital language of business, An Indian perspective. Indian Accounting Review, 6(1): 41-59.

\section{Weblinks}

www.xbrl.org

www.iasb.org

www.mca.gov.in

www.xbrl.gov.in. 